\title{
Test of Learning Capability Model in Nepalese Commercial Banks
}

\author{
Dilliram Bhandari, $\mathrm{PhD}$ \\ Lecturer \\ Faculty of Management, Shanker Dev Campus, Kathmandu, Tribhuvan University, Nepal \\ Email: drvandari@gmail.com
}

DOI: https://doi.org/10.3126/dristikon.v10i1.34544

\begin{abstract}
Learning and innovation are being threshold capabilities of modern organizations. Taking this into consideration, this study attempts to explore the learning orientation of organizational learning capability (OLC) and test a learning model in Nepalese commercial banks which have been operating in a highly competitive and volatile environment with strict regulatory frameworks. A descriptive research design has been followed to explore the state of OLC in Nepalese commercial banks. The population of this study comprised of all 27 commercial banks of Nepal and the sample frame for this study included 11 commercial banks, out of which, three were publicly-owned banks and eight were private sector banks. The informants of this study are the middle and top-level employees of the sample banks from both branch and corporate (head) offices. Altogether 415 questionnaires were distributed, out of these 265 questionnaires were returned and finally, 245 responses were used for further analysis. A descriptive research design was followed to explore the state of OLC in Nepalese commercial banks. The development of the measurement model of OLC was achieved at two levelsexploratory factor analysis (EFA) and confirmatory factor analysis (CFA). This study proposes a leaning model for Nepalese commercial banks. This is expected to give the first insight into the items and constructs to build the learning capability model for enhanced organizational effectiveness. This study also showed that Nepalese commercial banks are in poor state of OLC that shows they not oriented towards learning for building their capabilities.
\end{abstract}

Keywords: organizational learning capability, commercial banks, factor analysis

\section{Introduction}

\section{Background}

In recent years, the global competitive landscape has been changing rapidly. Businesses today are facing ample of challenges which arise due to globalization, use of technology, intellectual capital, unpredictable change, and other volatile socio-economic environments. In response to these challenges, businesses must improve and innovate continuously to grow and sustain. Resistance to innovation may result in business collapse (Leavy, 1998).

The success of organizations is built upon organizations' and individuals' speeding learning. Thus, learning in an organization is the key for organizations to sustain competitive advantages. As Jude-York (1991) points out, organizations striving in today's fast-changing 
marketplace are facing the need to have employees who know how to learn and who can quickly retool and be ready for new challenges. The idea behind the learning organization (LO) includes the notions of adaptability, flexibility, avoidance of stability traps, experimentation, rethinking means and ends, the realization of human potential to learn in the service of business purposes, and creation of human development (Argyris, 1999). OLC is dependent on invisible assets as knowledge (Sinkoula, Baker, \& Ordewier, 1997). Thite (2004) concludes that LO attracts and retains the best talent by entering into a psychological contract with its employees that motivates them to generate knowledge for their professional skills.

\section{Research Problem}

Organizational learning prioritizes the creation and acquisition of new knowledge, and emphasizes the role of people in the creation and utilization of that knowledge (Denton, 1998). It presents an important route to performance, success and competitive advantage for the organizations (Dunphy \& Griffths, 1998). According to Drucker (1993) "value is created by productivity and innovation" and organizations must acquire knowledge as a source of sustainable competitive advantage.

Nepalese banking industry has turned to be very competitive with liberalization and globalization of the economy. Under such a situation, innovation is at the heart of the the industry to withstand competition and achieve sustainability in a small economy that is moving towards globalization. Commercial banks are selected for this study as learning and adapting to the changing environment are the most important success factors for them. This study is based on middle and top-level employees assuming that they have a better understanding of the existence of learning orientation in their respective organizations. This study aimed at addressing the following research questions.

- Do the commercial banks in Nepal are oriented towards building learning capability?

- Is the proposed learning capability model for Nepalese commercial banks reliable and valid?

\section{Research Objectives}

This study attempts to achieve the following objectives.

- To explore the learning orientation of Nepalese commercial banks.

- To test the proposed learning capability model for Nepalese commercial banks. reliable and valid.

\section{Rationale of the Paper}

In service sector organizations, OP is largely affected by customer service excellence leading to customer satisfaction and retention. In this sector, firms can gain competitive 
advantage through superior customer services that go beyond their expectations. Hence, it is important for organizations to adopt the learning orientation for organizational success. However, as the capability to learn does not naturally and readily occur within organizations, it is imperative for organizations to ensure that resources allocated and efforts made to instill learning within organizations.

This study proposes a leaning model for Nepalese commercial banks. It also aims to assess the learning capability of the banks. It allows them to focus on creating a learning environment and link OLC with other aspects. It is further expected to help them to formulate learning policies and programs as well as their implementation for coping with the organizational situations more effectively.

\section{Literature Review}

\section{Measurement of Organizational Learning Capability}

The learning organization (LO) is one that adopts specific strategies, mechanisms, and practices that encourage its members to learn continuously so that they can adapt to the changing business environment (Senge, 1990; Mills \& Friesen, 1992). These strategies, mechanisms, and practices are the "learning capability" of the organization (Goh, 1998). Ulrich et al. (1993) also used the term "learning capability" to refer to "building and diffusing learning capability", while DiBella et al. (1996) refer to them as "developing OLC".

Learning in organizations is defined as a process that increases the actionable knowledge of the organization and by which the members of the organization can conduct activities for interpretation, comprehension, and assimilation of tacit and explicit information (Ruiz-Mercader, Merono-Cerdan, \& Sabater-Sanchez, 2006). OL is concerned with developing knowledge related to the relationships among actions, consequences, and the environment. In other words, the goal of OL is knowledge development (Duncan \& Weiss, 1979). OL is a continuous process of knowledge creation, acquisition, and transformation (Neilson, 1997). Kang, Morris, and Snell (2007) demonstrate that firms need to not only develop strategies based on core knowledge and capabilities but also must work towards acquiring, transferring, and integrating new knowledge, facilitating the process of OL to create the valuable human capital required to adapt to dynamic environments. OL has been considered as routine-based, history-dependent, and target-oriented (Levitt \& March, 1988). Ju, Li and Lee (2006) also indicate that $\mathrm{OL}$ is difficult to achieve, especially for the sharing of tacit knowledge, and the key elements to enable learning are channels of communication.

Although the LO literature is vast and takes various forms, as Argyris (1999) points out, the central idea behind the LO is broadly shared. The idea includes the notions of adaptability, flexibility, avoidance of stability traps, experimentation, rethinking means and 
ends, the realization of human potential to learn in the service of business purposes, and creation of human development.

Many researchers have proposed some distinct measurement dimensions for OL, such as the work of Huber (1991) and Pace et al. (1998), based on Levitt and March's (1988) research to develop organizational learning profiles. Hanvanich et al. (2006) focused on learning orientation and organizational memory to provide a complete view of firms' learning characteristics.

Learning organization is represented by seven dimensions developed by Watkins and Marsick (1993). The dimensions are continuous learning, dialogue and inquiry, team learning, embedded system, system connections, empowerment, and leadership.

Huber (1991) claims the learning in organizational must go through knowledge acquisition, information distribution, information interpretation, and information memory processes. Like a living system, organizations can learn through knowledge acquisition, information distribution, and interpretation as well as organizational memory (Amy, 2005). The process of OL may contain information acquisition, information interpretation, and behavioral and cognitive changes.

Theriou and Chatzoglou (2008) adopted four constructs namely commitment to learning and empowerment, systems perspective and clarity of purpose and mission, openness and experimentation, and organizational memory to measure OLC.

Lin and Kuo (2007) classified OLC into four factors: information-sharing patterns, inquiry climate, learning practices, and achievement mindset. Ho (2008) classified organizational learning as learning practices, information sharing patterns, inquiry climate, and achievement mindset. Shakya (2012) used collective learning, culture and metaphor, process and system, continuous improvement, total quality management, and knowledge management as the components of learning.

\section{Table1}

Summary of Organizational Learning Capability Used by Different Researchers

\begin{tabular}{ll}
\hline \multicolumn{1}{c}{ Researchers } & \multicolumn{1}{c}{ OLC Dimensions } \\
\hline Huber (1991) & $\begin{array}{l}\text { Knowledge acquisition, information distribution, } \\
\text { information interpretation, and information memory } \\
\text { processes }\end{array}$
\end{tabular}

Neilson (1997)

Knowledge creation, acquisition, and transformation.

Amy (2005)

Knowledge acquisition, information distribution, and interpretation as well as organizational memory 


\begin{tabular}{ll}
\hline \multicolumn{1}{c}{ Researchers } & \multicolumn{1}{c}{ OLC Dimensions } \\
\hline Lin and Kuo (2007) & $\begin{array}{l}\text { Information-sharing patterns, inquiry climate, learning } \\
\text { practices, and achievement mindset }\end{array}$ \\
Theriou and Chatzoglou (2008) & $\begin{array}{l}\text { Commitment to learning and empowerment, systems } \\
\text { perspective and clarity of purpose and mission, openness } \\
\text { and experimentation and organizational memory } \\
\text { Learning practices, information sharing patterns, inquiry } \\
\text { climate, and achievement mindset }\end{array}$ \\
Sho (2008) & $\begin{array}{l}\text { Collective learning, culture and metaphor, process and } \\
\text { system, continuous improvement, total quality } \\
\text { management, and knowledge management }\end{array}$ \\
\hline
\end{tabular}

Based on the above literature, OLC was measured through 12 items (Table 2) taken from works of Galer and Heijden (1992), Goh and Richards (1997), Hult and Ferrell (1997), Calantone, Cavusgil, and Zhao (2002), Sinkoula et al. (1997), and Shakya (2012).

Table 2

Measures of Organizational Learning Capability

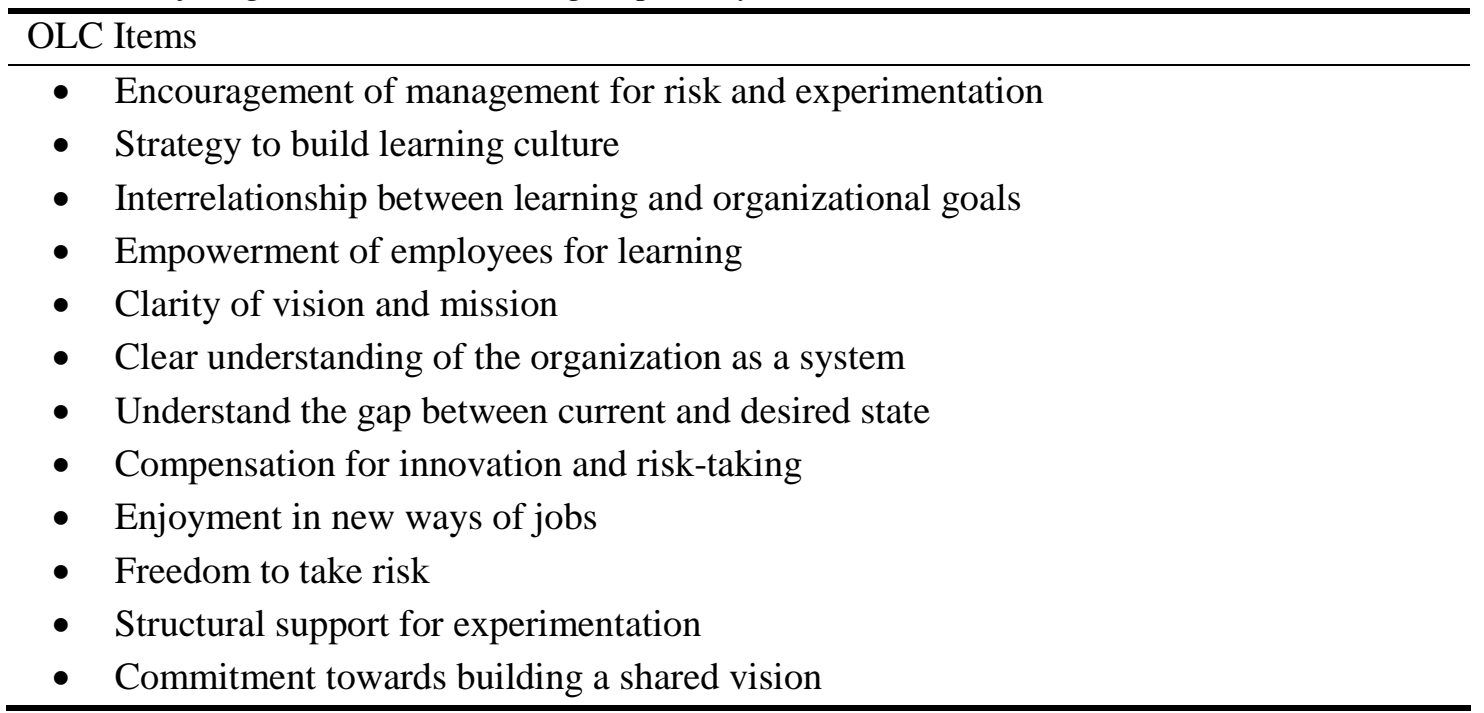

\section{Methods and Materials}

The main objective of this study was to explore the learning orientation of Nepalese commercial banks. A survey research strategy was adopted to achieve the study objective and the descriptive research design was followed to explore the state of OLC in Nepalese 
commercial banks. This study had adopted the quantitative approach to assess the existence of OLC as perceived by the employees were measured through a Likert scale ranging from 1 to 7 (Theriou \& Chatzoglou, 2008; Lin\& Kuo, 2007).

The population of this study was comprised of all 27 commercial banksof Nepal. To achieve sufficient sample size and generalization of the result, the sample frame for this study included 11 commercial banks, out of which, three were publicly-owned banks and eight were private-sector banks.

The banking industry was selected for this study since it is regarded as one of the most successful industries in Nepal. Banks provide service to the people. The nature and types of services provided by commercial banks are knowledge-based and their performances are largely determined by the dynamic capabilities they develop through learning. With the changing environment and customer expectations, learning orientations are likely to come into consideration in Nepalese financial institutions. The banking sector is regarded as information and knowledge-intensive.

The content validity of the questionnaire is expected to be high due to it was discussed with two HR managers and two senior bank managers and was revised and modified based on their advice and suggestions. Finally, the questionnaire was pretested with 20 senior-level employees selected randomly from the sample banks. It was performed to establish content validity (Zikmund, 2003). Based on a detailed analysis of the questionnaire, it was further modified and finalized for administration.

The informants of this study were the middle and top-level employees of the sample banks from both branch and corporate (head) office who were expected to have better knowledge and understandings of the existence of OLC in their respective organizations better than other employees. The names of the top and middle-level employees of the sample organizations were collected from their respective HR departments and questionnaires were distributed to them randomly to minimize the sampling errors.

At least 30 employees from each organization were approached to respond about the existence of OLC in their respective organizations. Altogether 415 questionnaires were distributed, out of these 265 questionnaires were returned, the response rate was $64 \%$ which may be taken highly satisfactory in survey research design. A total of 20 questions were removed as they were not in usable forms due to multiple non-responses. Finally, 245 responses were used for further analysis. According to Kline (2005), the typical sample size in studies where SEM is used is about 200 cases. Hence, the number of the response of this study may be regarded as satisfactory for model building through SEM.

The development of the measurement model of the study constructs was achieved at two levels- exploratory factor analysis (EFA) and confirmatory factor analysis (CFA). EFA of 
OLC was done to extract the latent factors or dimensions from the measured items. CFA was used to test whether measures of a construct are consistent with a researcher's understanding of the nature of that construct (or factor). CFA was done at two levels. The first order CFA involved the development and evaluation of the measurement model of different items of OLC practices to check the unidimensionality of each dimension of OLC. The second-order CFA was employed to confirm that the theorized dimensions of OLC practices load into their respective constructs. As the first-order factor, the second-order factors are also completely latent and unobservable.

\section{Results and Discussion}

The data was analyzed and presented in three steps. In the first step, the EFA of OLC was done to extract the latent factors or dimensions from the measured items. After the identification of latent factors representing OLC, descriptive analysis was conducted to assess the state of OLC in Nepalese commercial banks (second step). The statistical tools such as mean, standard deviation, and ANOVA were used for this. In the third and final step, CFA was used to test whether measures of a construct are consistent with the researcher's understanding of the nature of that construct (or factor).

Before conducting EFA, some conditions were checked. The missing values were checked before running the EFA and CFA. One approach to handling missing data is to substitute the variable mean for all missing values on that variable. This is a very common approach, and it is still an option for handling missing data in many procedures. Following this, the missing values were replaced with the average value of the items. Likewise, the Mahalanobis distance (Mahalanobis, 1936) statistics ( $\mathrm{p}<0.05)$ was calculated to identify the multivariate outliersbefore conducting the second-order CFA. The Mahalanobis distance is a generalization of the distance concept to $\mathrm{P}$ dimensional correlated data. It uses an appropriate covariance matrix to take account of differences in variable variances and correlations between variables. It is frequently employed in multivariate statistical methods. Five outlier responses were detected and removed from further analysis.

\section{Exploratory Factor Analysis of Organizational Learning Capability}

EFA was used to identify the underlying dimensions of OLC in Nepalese commercial banks measured through the employees' perspective. The 12 items in the questionnaire are analyzed using principal component analysis with varimax rotation. 
Table 3

Exploratory Factor Analysis of Organizational Learning Capability

\begin{tabular}{|c|c|c|c|c|}
\hline & $\begin{array}{c}\text { Factor } 1 \\
\text { System } \\
\text { perspective }\end{array}$ & $\begin{array}{c}\text { Factor } 2 \\
\text { Openness and } \\
\text { experimentation }\end{array}$ & $\begin{array}{c}\text { Factor } 3 \\
\text { Commitment } \\
\text { to learning }\end{array}$ & $\overline{\text { Communalities }}$ \\
\hline Cronbach's $\alpha$ & 0.883 & 0.894 & 0.873 & \\
\hline Eigenvalue & 6.036 & 1.752 & 1.354 & \\
\hline $\begin{array}{l}\% \text { of variance explained } \\
\text { (Total } 76.181 \% \text { ) }\end{array}$ & 50.296 & 14.603 & 11.282 & \\
\hline $\begin{array}{l}\text { Encouragement of management for } \\
\text { risk and experimentation } \\
\text { COMMIT1 }\end{array}$ & & & 0.831 & 0.772 \\
\hline $\begin{array}{l}\text { Strategy to build learning culture } \\
\text { COMMIT } 2\end{array}$ & & & 0.849 & 0.832 \\
\hline $\begin{array}{l}\text { Interrelationship between learning } \\
\text { and organizational goals COMMIT3 }\end{array}$ & & & 0.752 & 0.648 \\
\hline $\begin{array}{l}\text { Empowerment of employees for } \\
\text { learning COMMIT4 }\end{array}$ & & & 0.769 & 0.711 \\
\hline $\begin{array}{l}\text { Clarity of vision and mission } \\
\text { CLARITY1 }\end{array}$ & 0.813 & & & 0.750 \\
\hline $\begin{array}{l}\text { Clear understanding of the } \\
\text { organization as a system CLARITY2 }\end{array}$ & 0.869 & & & 0.813 \\
\hline $\begin{array}{l}\text { Understand the gap between current } \\
\text { and desired state CLARITY3 }\end{array}$ & 0.776 & & & 0.748 \\
\hline $\begin{array}{l}\text { Commitment towards building a } \\
\text { shared vision } \\
\text { CLARITY4 }\end{array}$ & 0.736 & & & 0.710 \\
\hline $\begin{array}{l}\text { Enjoyment in new ways of jobs } \\
\text { OPEN1 }\end{array}$ & 0.447 & 0.682 & & 0.716 \\
\hline Freedom to take risk OPEN2 & & 0.878 & & 0.824 \\
\hline $\begin{array}{l}\text { Structural support for } \\
\text { experimentation } \\
\text { OPEN3 }\end{array}$ & & 0.886 & & 0.821 \\
\hline $\begin{array}{l}\text { Compensation for innovation and } \\
\text { risk-taking OPEN } 4\end{array}$ & & 0.828 & & 0.798 \\
\hline KMO Measure of Sampling Adequacy & & & 0.862 & \\
\hline Bartlett's Test of Sphericity & & & 2063.193 & \\
\hline Approx. Chi-Square DF & & & 66 & \\
\hline Sig. & & & 0.000 & \\
\hline
\end{tabular}


The theoretical concepts of OLC used in this study were taken from previous studies that provided theoretical justification for the present study. Some of the items were modified to match the OLC of commercial banks. The result of the EFA of OLC has been presented in table 3.

As outlined in table 3, three factors of OLC were extracted, which accounted for $76.181 \%$ of total variance explained. Bartlett's Test of Sphericity $(\mathrm{p}<0.001)$ as shown by the above table shows that the factor model is highly appropriate (Norusis,1994). The KMO measure of sampling adequacy (0.862) is above the cut point of 0.6 (Norusis,1994). It shows that the samples are adequate for the factor model. All the factors have eigenvalues over one ranging from 1.354 to 6.036 .

The 12 items representing different dimensions of OLC were classified under three factors namely commitment to learning and empowerment, system perspective, and clarity of purpose and mission and openness and experimentation.

The analysis showed all the factors have Cronbach's $\alpha$ value higher than 0.7 (0.873 to 0.894). It signified the factors are reliable. The loadings of each item were greater than 0.50 and averaging out to greater than 0.70 for each factor. It revealed the factors had high convergent validity. The correlations between the factors are less than 0.7 (Table 4) which satisfied discriminant validity (Gaskin \& Lim, 2016).

\section{Table 4}

Factor Correlation Matrix of Organizational Learning Capability

\begin{tabular}{|c|c|c|c|}
\hline Factors & $\begin{array}{l}\text { Openness and } \\
\text { experimentation }\end{array}$ & $\begin{array}{l}\text { Commitment } \\
\text { to learning and } \\
\text { empowerment }\end{array}$ & $\begin{array}{l}\text { System perspective } \\
\text { and clarity of } \\
\text { purpose and mission }\end{array}$ \\
\hline Openness and experimentation & 1.000 & & \\
\hline $\begin{array}{l}\text { Commitment to learning and } \\
\text { empowerment }\end{array}$ & 0.447 & 1.000 & \\
\hline $\begin{array}{l}\text { System perspective and clarity of } \\
\text { purpose and mission }\end{array}$ & 0.524 & 0.424 & 1.000 \\
\hline
\end{tabular}

\section{Descriptive Analysis of Organizational Learning Capability}

The EFA explored three factors named as the commitment to learning and empowerment, system perspective and clarity of purpose and mission and openness and experimentation. Each dimension was measured as a latent variable comprising several items. The descriptive statistics of each dimension are presented in table 5. 
Table 5

Descriptive Analysis of OLC Dimensions $N=240$

\begin{tabular}{|c|c|c|c|c|c|c|c|}
\hline OLC Dimensions & $\begin{array}{l}\text { No of } \\
\text { Items }\end{array}$ & Public & $\begin{array}{l}\text { Mean } \\
\text { Private }\end{array}$ & & $\begin{array}{l}\text { St. } \\
\text { Dev. }\end{array}$ & $\mathrm{F}$ & Sig \\
\hline Commitment to Learning and Empowerment & & 3.50 & 3.78 & 3.70 & 1.17 & 2.91 & 0.09 \\
\hline $\begin{array}{l}\text { System Perspective and Clarity of Purpose } \\
\text { and Mission }\end{array}$ & & 3.36 & 3.68 & 3.59 & 1.04 & 5.11 & 0.03 \\
\hline Openness and Experimentation & & 3.22 & 3.75 & 53.61 & 1.07 & 12.87 & 0.00 \\
\hline
\end{tabular}

The descriptive analysis of OLC dimensions revealed that all the dimensions namely commitment to learning and empowerment (Mean-3.70, SD-1.17), system perspective and clarity of purpose and mission (Mean-3.59, SD-1.04) and openness and experimentation (Mean-3.61, SD-1.07) were perceived unsatisfactory by the employees in Nepalese commercial banks (Mean<4). Both types of banks (public and private) were found to have an unsatisfactory state of all three dimensions of OLC. However, the private commercial banks were found to have a better practice of OLC than the public banks in all three dimensions. Such difference was not significant with a commitment to learning and empowerment (F-2.91, P-.09) and system perspective and clarity of purpose and mission (F-5.11, P-0.03). A significant difference between the public and private commercial banks with openness and experimentation (F-12.87, P-0.00) could be noticed.

The descriptive analysis depicted that the OLC of Nepalese commercial banks is poor. It signaled that knowledge development within the banks is slow. They are found to give less priority to empowering the employees for learning. They don't give much emphasis on the development of learning mechanisms, culture, and strategy. It indicates they still do not take learning as a way of organizational survival.

\section{Confirmatory Factor Analysis of Organizational Learning Capability}

The test of the OLC scale/theory was achieved through two steps. In the first step, firstorder CFAs of three OLC dimensions obtained through EFA was done to test the unidimensionality. Finally, the second-order CFA was done to test the factor model of OLC representing different dimensions.

\section{Initial Model Fit and Modification in Organizational Learning Capability Dimensions - First-Order Confirmatory Factor Analysis}

OLC emerged as a three-dimensional construct namely commitment to learning and empowerment, system perspective, and clarity of purpose and mission and openness and 
experimentation. This section presents the key findings of the initial measurement model of OLC dimensions extracted from EFA.

Commitment to Learning and Empowerment: Initial Findings. The initial analysis of four items of commitment to learning and empowerment revealed three model fit indices namely CMIN/DF (3.960), CFI (0.989), SRMR (0.028), and RMSEA (0.06) were found above the recommended threshold levels.

\section{Table 6}

Commitment to Learning and Empowerment: Summary of Initial Findings

\begin{tabular}{|c|c|c|c|c|c|c|c|}
\hline $\begin{array}{l}\text { Question } \\
\text { Items }\end{array}$ & \multicolumn{3}{|c|}{ Items wording } & \multicolumn{2}{|c|}{ Initial St. Loadings } & \multicolumn{2}{|c|}{ Final St. Loadings } \\
\hline COMMIT1 & \multicolumn{3}{|c|}{$\begin{array}{l}\text { Encouragement of management } \\
\text { for risk and experimentation }\end{array}$} & \multicolumn{2}{|l|}{0.815} & \multicolumn{2}{|l|}{0.815} \\
\hline COMMIT2 & \multicolumn{3}{|c|}{$\begin{array}{l}\text { Strategy to build a learning } \\
\text { culture }\end{array}$} & 0.930 & & \multicolumn{2}{|l|}{0.930} \\
\hline COMMIT3 & \multicolumn{3}{|c|}{$\begin{array}{l}\text { Interrelationship between learning } \\
\text { and organizational goals }\end{array}$} & 0.693 & & \multicolumn{2}{|l|}{0.693} \\
\hline COMMIT4 & \multicolumn{3}{|c|}{$\begin{array}{l}\text { Empowerment of employees for } \\
\text { learning }\end{array}$} & 0.758 & & \multicolumn{2}{|l|}{0.758} \\
\hline \multicolumn{8}{|c|}{ Achieved Fit Indices } \\
\hline \multirow{2}{*}{$\begin{array}{l}\text { Mode of } \\
\text { analysis }\end{array}$} & CMIN/DF & AVE & \multicolumn{2}{|c|}{ CFI } & SRMR & RMSEA & $\mathrm{CR}$ \\
\hline & $<3$ & $>0.5$ & \multicolumn{2}{|c|}{$>0.9$} & $<0.08$ & $<0.06$ & $>0.7$ \\
\hline Initial & 3.960 & 0.646 & \multicolumn{2}{|c|}{0.989} & 0.028 & 0.06 & 0.878 \\
\hline Final & 3.960 & 0.646 & \multicolumn{2}{|c|}{0.989} & 0.028 & 0.06 & 0.878 \\
\hline
\end{tabular}

Note. Composite Construct Reliability: 0.878.

The primary model of commitment to learning and empowerment may be regarded as satisfactory on the ground of three acceptable model fit indices. The final model revealed that all the factors loading of the four items were above 0.7 . The composite reliability for this construct is 0.878 which was well above the acceptable level of 0.5 . The AVE by these four items i.e. 0.646 was above the recommended threshold of 0.5 . This indicated that the four items of commitment to learning and empowerment could be considered reliable as well as valid for the measurement of the dimension. 
System Perspective and Clarity of Purpose and Mission: Initial Findings. The initial analysis of system perspective and clarity of purpose and mission with four items revealed two model fit indices namely CMIN/DF (15.323) and RMSEA (0.241) were below the acceptable threshold levels. The other two fit indices CFI (0.949) and SRMR (0.052) were above the acceptable thresholds. Overall, the primary model of system perspective and clarity of purpose and mission needed some improvements.

Table 7

System Perspective and Clarity of Purpose and Mission: Summary of Initial Findings

\begin{tabular}{|c|c|c|c|c|c|c|c|c|}
\hline $\begin{array}{l}\text { Question } \\
\text { Items }\end{array}$ & \multicolumn{4}{|c|}{ Items wording } & \multicolumn{2}{|c|}{$\begin{array}{l}\text { Initial St. } \\
\text { Loadings }\end{array}$} & & $\begin{array}{l}\text { al St. } \\
\text { dings }\end{array}$ \\
\hline CLARITY1 & \multicolumn{4}{|c|}{ Clarity of vision and mission } & \multicolumn{2}{|c|}{0.800} & & 748 \\
\hline CLARITY2 & \multicolumn{4}{|c|}{ Clear understanding of the organization as a system } & \multicolumn{2}{|c|}{0.865} & & 899 \\
\hline CLARITY3 & \multicolumn{4}{|c|}{$\begin{array}{l}\text { Understand the gap between the current and desired } \\
\text { state }\end{array}$} & \multicolumn{2}{|c|}{0.829} & \multicolumn{2}{|c|}{0.843} \\
\hline CLARITY4 & \multicolumn{4}{|c|}{ Commitment towards building a shared vision } & \multicolumn{2}{|c|}{0.745} & \multicolumn{2}{|c|}{0.680} \\
\hline \multicolumn{9}{|c|}{ Achieved Fit Indices } \\
\hline \multirow{2}{*}{$\begin{array}{l}\text { Mode of } \\
\text { analysis }\end{array}$} & CMIN/DF & AVE & CFI & SR & & $\mathrm{RM}$ & & $\mathrm{CR}$ \\
\hline & $<3$ & $>0.5$ & $>0.9$ & $<0$. & & $<0$. & & $>0.7$ \\
\hline Initial & 15.323 & 0.658 & 0.949 & 0.0 & & 0.2 & & 0.885 \\
\hline Final & 3.297 & 0.635 & 0.996 & 0.0 & & 0.0 & & 0.873 \\
\hline
\end{tabular}

Note. Composite Construct Reliability: 0.873.

The MIs revealed that there is a high standardize residual covariance between CLARITY1 (Clarity of vision and mission) and CLARITY4 (Commitment towards building shared vision). Hence, they were made parameter-free to each other to improve the model.

The final model revealed that all the factors loading of the four items are above 0.5 . The final composite reliability for this construct was 0.873 well above the acceptable level of 0.7 . The AVE by these four items i.e. 0.635 was above the recommended threshold of 0.5 (Hu \& Bentler, 1999). This showed that the four items of system perspective and clarity of purpose and mission could be considered reliable as well as valid for this dimension measure.

Openness and experimentation: initial findings. The initial analysis of openness and experimentation measured with four items revealed all the model fit indices namely CMIN/DF 
(0.872), CFI (1.000), SRMR (0.012), and RMSEA (0.000) were well above the acceptable threshold levels.

\section{Table 8}

Openness and Experimentation: Summary of Initial Findings

\begin{tabular}{|c|c|c|c|c|c|c|}
\hline $\begin{array}{l}\text { Question } \\
\text { Items }\end{array}$ & \multicolumn{2}{|c|}{ Items wording } & \multicolumn{2}{|c|}{ Initial St. Loadings } & \multicolumn{2}{|c|}{ Final St. Loadings } \\
\hline OPEN1 & \multicolumn{2}{|c|}{$\begin{array}{l}\text { Enjoyment in new ways of } \\
\text { jobs }\end{array}$} & & .742 & & 0.742 \\
\hline OPEN2 & \multicolumn{2}{|c|}{ Freedom to take risk } & & .865 & & 0.865 \\
\hline OPEN3 & \multicolumn{2}{|c|}{$\begin{array}{l}\text { Structural support for } \\
\text { experimentation }\end{array}$} & & .880 & & 0.880 \\
\hline OPEN4 & \multicolumn{2}{|c|}{$\begin{array}{l}\text { Compensation for innovation } \\
\text { and risk-taking }\end{array}$} & & .816 & & 0.816 \\
\hline \multicolumn{7}{|c|}{ Achieved Fit Indices } \\
\hline \multirow{2}{*}{$\begin{array}{l}\text { Mode of } \\
\text { analysis }\end{array}$} & CMIN/DF & AVE & CFI & SRMR & RMSEA & $\mathrm{CR}$ \\
\hline & $<3$ & $>0.5$ & $>0.9$ & $<0.08$ & $<0.06$ & $>0.7$ \\
\hline Initial & 0.872 & 0.685 & 1.000 & 0.012 & 0.000 & 0.896 \\
\hline Final & 0.872 & 0.685 & 1.000 & 0.012 & 0.000 & 0.896 \\
\hline
\end{tabular}

Note. Composite Construct Reliability: 0.896

The model revealed that all the factor loadings of the four items are above 0.7. The final composite reliability for this construct was 0.896 well above the acceptable level of 0.7 . The average variance explained (AVE) by these four items i.e. 0.685 was above the recommended threshold of 0.5 . This revealed that the four items of openness and experimentation could be considered reliable as well as valid for this construct measure.

Development of Organizational Learning Capability Model- Second-order Confirmatory Factor Analysis. After the assessment of the model fit of each OLC dimension (first-order CFA), the second-order CFA of the OLC construct was conducted. This assesses whether the OLC dimensions were correlated and structural relationships between them and the main construct OLC exists or not. It posits that the first-order factors or dimensions (OLC dimensions) are sub-dimensions of a broader and more encompassing second-order factor (OLC). 
Table 9

Summary of Initial Findings of Organizational Learning Capability Using Confirmatory Factor Analysis

\begin{tabular}{|c|c|c|c|c|c|c|c|c|}
\hline $\begin{array}{l}\text { OLC } \\
\text { Dimensions }\end{array}$ & $\begin{array}{l}\text { Number } \\
\text { of items }\end{array}$ & $\begin{array}{l}\text { CMIN/DF } \\
<3\end{array}$ & AVE & $\begin{array}{l}\mathrm{CFI} \\
>0.9\end{array}$ & $\begin{array}{l}\text { SRMR } \\
<0.08\end{array}$ & $\begin{array}{l}\text { RMSEA } \\
<0.06\end{array}$ & $\overline{\mathrm{CR}}$ & Remarks \\
\hline $\begin{array}{l}\text { Commitment to } \\
\text { learning and } \\
\text { empowerment }\end{array}$ & 4 & 3.960 & 0.646 & 0.989 & 0.028 & 0.06 & 0.878 & $\begin{array}{l}\text { No } \\
\text { modification }\end{array}$ \\
\hline $\begin{array}{l}\text { System } \\
\text { perspective and } \\
\text { clarity of } \\
\text { purpose and } \\
\text { mission }\end{array}$ & 4 & 3.297 & 0.635 & 0.996 & 0.013 & 0.06 & 0.873 & $\begin{array}{l}\text { CLARITY1 } \\
\text { (clarity of } \\
\text { vision and } \\
\text { mission) and } \\
\text { CLARITY4 } \\
\text { (commitment } \\
\text { towards } \\
\text { building shared } \\
\text { vision) are } \\
\text { made } \\
\text { parameter-free. }\end{array}$ \\
\hline $\begin{array}{l}\text { Openness and } \\
\text { experimentation }\end{array}$ & 4 & 0.872 & 0.685 & 1.000 & 0.012 & 0.000 & 0.896 & $\begin{array}{l}\text { No } \\
\text { modification }\end{array}$ \\
\hline
\end{tabular}

Primary Model. The second-order CFA of OLC was done to check whether the three dimensions with 12 items of OLC (Commitment to learning and empowerment, system perspective, and clarity of purpose and mission and openness and experimentation) are valid and reliable to represent the main construct OLC.

Out of the four model fit indices used in this study, CMIN/DF (5.511), CFI (0.887), and RMSEA (0.135) showed poor fit. Hence, the 12 items model of OLC needed further modification.

Modified and Final Model. Since the primary model of second-order CFA of 12 items of OLC showed poor fit, it was modified for improvement. For this, the model was restructured using the MIs and the final model of OLC was developed. Two items from the primary model of OLC dimensions were removed on the ground of item content analysis, MIs, and standardized residual covariances. They were items COMMIT4 (Empowerment of employees for learning) and CLARITY4 (Commitment towards building shared vision). Finally, the 10 items model was tested for reliability, validity, and model fit. 
Table 10

Primary Model Fit Measures

\begin{tabular}{llll}
\hline Measure & Estimate & $\begin{array}{l}\text { Recommended } \\
\text { threshold }\end{array}$ & Interpretation \\
\hline CMIN & 281.036 & -- & -- \\
DF & 51 & -- & -- \\
CMIN/DF & 5.511 & Between 1 and 3 & Terrible \\
CFI & 0.887 & $>0.95$ & Need More DF \\
SRMR & 0.084 & $<0.08$ & Acceptable \\
RMSEA & 0.135 & $<0.06$ & Terrible \\
\hline
\end{tabular}

Note. Interpretation: Gaskin and Lim (2016).

The model fit measures of the model provided a satisfactory result. CMIN/DF (4.993), SRMR (0.079), RMSEA (0.052), CFI (0.918) were above the recommended threshold levels and the model could be used for further analysis.

Table 11

Model Fit Measures

\begin{tabular}{llll}
\hline Measure & Estimate & $\begin{array}{l}\text { Recommended } \\
\text { threshold }\end{array}$ & Interpretation \\
\hline CMIN & 159.760 & -- & -- \\
DF & 32 & -- & -- \\
CMIN/DF & 4.993 & Between 1 and 3 & Acceptable \\
CFI & 0.918 & $>0.95$ & Acceptable \\
SRMR & 0.079 & $<0.08$ & Excellent \\
RMSEA & 0.052 & $<0.06$ & Acceptable \\
\hline
\end{tabular}

Note. Interpretation: Gaskin and Lim (2016).

CRs of all the latent variables ( 0.870 to 0.897$)$ were greater than the acceptable limit of 0.70 . The average-variance extracted for all the factors is $>0.5$ which was acceptable. Besides, the AVE for each construct is $>0.50$, which further supported the convergent validity of the constructs (0.692 to 0.687). All the square root of the AVE values of all the OLC factors (diagonal values) were greater than the inter-construct correlations (loadings) which supported the discriminant validity of the constructs. 


\section{Figure 1}

Final Measurement Model Organizational Learning Capability

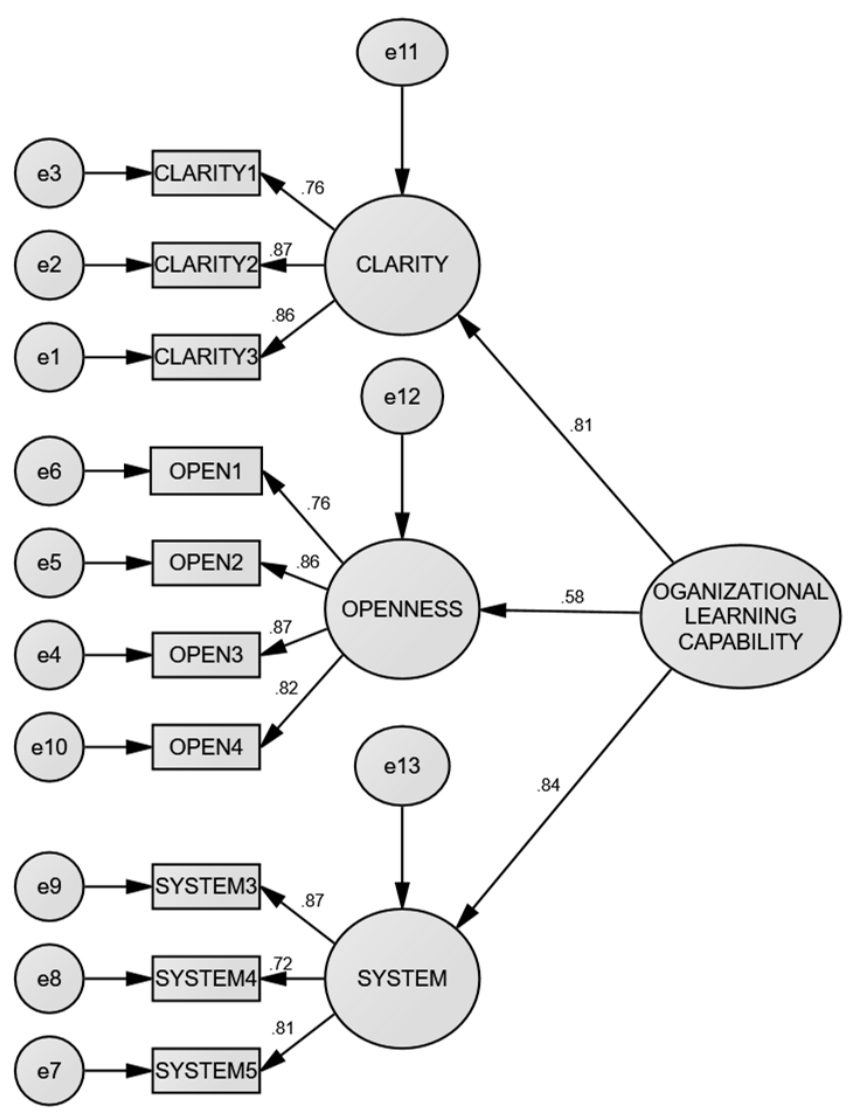

\section{Table 12}

Final Model Validity Measures of Organizational Learning Capability

\begin{tabular}{lcll}
\hline OLC Dimensions & CR & $\begin{array}{c}\text { AVE } \\
\text { System Perspective } \\
\text { and Clarity of } \\
\text { Purpose and Mission empowerment }\end{array}$ & $\begin{array}{l}\text { Commitment to Openness and } \\
\text { learning and }\end{array}$ \\
\hline
\end{tabular}

System Perspective and Clarity

of Purpose and Mission

$0.8700 .692 \mathbf{0 . 8 3 2}$

Commitment to learning and

empowerment

$0.8970 .6870 .465^{* * *}$

0.829

Openness and Experimentation $0.8440 .644 \quad 0.674 * * *$

$0.483^{* * *}$

0.803 
The results of the CFA analysis of the 10 items model of OLC indicated a good fit between the model and the data and may be taken as suitable model for OLC in Nepalese commercial banks. Figure 1 presents the final model of OLC.

Based on the above analysis the final measurement model of OLC with standardized loadings, CR, and AVE is presented in table 13.

\section{Table 13}

Final Measurement Model of OLC

\begin{tabular}{|c|c|c|c|c|}
\hline Construct & Measurement items & $\begin{array}{l}\text { Standardize } \\
\text { loading }\end{array}$ & AVE & $\mathrm{CR}$ \\
\hline \multirow{3}{*}{ OLC } & $\begin{array}{l}\text { System perspective and clarity } \\
\text { of purpose and mission }\end{array}$ & 0.806 & 0.561 & 0.789 \\
\hline & Openness and experimentation & 0.578 & & \\
\hline & $\begin{array}{l}\text { Commitment to learning and } \\
\text { empowerment }\end{array}$ & 0.836 & & \\
\hline \multirow{3}{*}{$\begin{array}{l}\text { System } \\
\text { perspective and } \\
\text { clarity of } \\
\text { purpose and } \\
\text { mission }\end{array}$} & CLARITY1 & 0.759 & & \\
\hline & CLARITY2 & 0.868 & 0.692 & 0.870 \\
\hline & CLARITY3 & 0.864 & & \\
\hline \multirow{4}{*}{$\begin{array}{l}\text { Openness and } \\
\text { experimentation }\end{array}$} & OPEN1 & 0.763 & 0.687 & 0.897 \\
\hline & OPEN2 & 0.857 & & \\
\hline & OPEN3 & 0.868 & & \\
\hline & OPEN4 & 0.823 & & \\
\hline \multirow{3}{*}{$\begin{array}{l}\text { Commitment to } \\
\text { learning and } \\
\text { empowerment }\end{array}$} & COMMIT1 & 0.869 & 0.644 & 0.844 \\
\hline & COMMIT2 & 0.720 & & \\
\hline & COMMIT3 & 0.812 & & \\
\hline
\end{tabular}

Table 13 shows that AVE by three dimensions of OLC is 0.561 which is above the acceptable threshold level (0.50). The CR of OLC as a construct is 0.789 which is also above the acceptable threshold level. Finally, the standardized loadings of all three dimensions $(0.578$ to 0.836 ) are well above acceptable threshold levels. In conclusion, the OLC model with three dimensions representing 10 items may be accepted for the structural model. 


\section{Discussion}

This study made an important contribution to understand the context of OLC in Nepalese commercial banks. Very little attention was made to build and test an OLC model in the Nepalese context before. This study proposed a leaning model for Nepalese commercial banks. It gives a first insight into the items and constructs to build a learning capability model for enhanced organizational effectiveness. This study showed a poor state of OLC in Nepalese commercial banks.

The poor learning capability of Nepalese commercial banks may be discussed in some perspectives. The high demand for middle and top-level executives in Nepalese commercial banks may be leading to a high turnover of their employees. This may be reducing learning orientation among the employees. Individual learning may be focused basically on career enhancement rather than overall organizational wellbeing. Nepalese commercial banks tend to focus on short term financial outcomes in the expense of strategic goals. There is a high focus for annual profit and employee pay and promotions are largely dictated by targets given to them. The banks are mostly found to competing with each other on a cost basis since they offer similar products which would be making them weaker learners than the differentiators. They are operating in strict regulatory frameworks that leave very little ground for openness and experimentation. The widespread nepotism and favoritism may be other reasons to reduce individual learning in the organization. Similarly, the rules and policies of the organizations leave very less ground of experimentation. The pay and promotions would not be linked with learning.

The poor state of learning orientation in Nepalese commercial banks can also be supported by Hofstede's (2001) powerdistance. Beyene et al. (2016) found high power distance has a dominant-negative effect on the learning orientation and innovation performance of the firms. Nepal is a relatively hierarchical society. Hierarchy in an organization is seen as reflecting inherent inequalities, centralization is common, subordinates expect to be told what to do and the ideal boss is a benevolent autocrat. This also hinders learning orientation in an organization.

\section{Conclusion}

In conclusion, the banking executives should focus on promoting a healthy environment for nurturing OL, as well as formulating effective OL policies and facilitates their implementation to maximize the total effects on OP. In other way, conditions need to exist in the organization for having the right learning environment or learning climate as Pedler et al. (1997) point out that employees should be encouraged to learn and share, systems should be established for learning and learning is valued and rewarded in the organization. 


\section{Limitations and Directions for Future Research}

The notable limitation of this study is its exclusive use of perceptual measures. This study was based on the responses by the employees at both branch level and corporate level employees. The OLC outcomes are more explicit at the branch level. Hence, future researchers can conduct research based on the employees at the branch level only. Finally, learning in an organization takes place at an individual, team, and organizational level. This study has focused on individual-level learning. Hence, future researchers may conduct research taking into the team and organizational level learning also into considerations.

\section{References}

Amy, A.H. (2005). Leaders as facilitators of organizational learning. [Unpublished Doctoral Dissertation], Regent University, Virginia Beach, VA.

Argyris, C. (1999). On organizational learning (2nd ed.). Blackwell, Oxford.

Calantone, R.J., Cavusgil, T.S., \& Zhao, Y. (2002). Learning orientation, firm innovation capability, and firm performance. Industrial Marketing Management, 31(6), 515-24.

DiBella, A. J., Nevis, E. C., \& Gould, J. M. (1996). Understanding organizational capability. Journal of Management Studies, 33(3), 361-79.

Drucker, P. (1993). Post Capitalist society. Oxford: Butterworth-Heinemann.

Duncan, R., \& Weiss, A. (1979). Organizational learning: Implications for organizational design. Research in Organization Behavior, 1, 75-123.

Dunphy, D., \& Griffths, A. (1998). The sustainable corporations. St Leonards: Allen and Unwin.

Galer, G., \& Heijden, K. (1992). How planners create organizational learning. Marketing Intelligence\& Planning, 10(6), 5-12.

Gaskin, J., \& Lim, J. (2016). Model fit measures. AMOS Plugin. Gaskination's Stat Wiki.

Goh, S.C., \& Richards, G. (1997). Benchmarking the learning capability of organizations, European Management Journal, 115(2), 575-88.

Hanvanich, S., Sivakumar, K., Tomas, G., \& Hult, M. (2006). The relationship of learning and memory with organizational performance: $7(1)$, the moderating role of turbulence. Journal of the Academy of Marketing Science, 34(4), 600-12.

Ho, L. (2008). What affects organizational performance? The linking of learning and knowledge management. Industrial Management \& Data Systems, 108 (9), 1234-54. 
Hofstede, G. (2001). Culture's consequences: comparing values, behaviors, institutions, and organizations Across Nations. Sage, Thousand Oaks, CA.

Hu, L., \& Bentler, P. M. (1999). Cutoff criteria for fit indexes in covariance structure analysis: Conventional criteria versus new alternatives. Structural Equation Modeling, 6, 1-55.

Huber, G. P. (1991). Organizational learning: the contributing processes and the literatures. Organization Science, 2, 88-115.

Huber, G. P. (1998). Synergies between organizational learning and creativity and innovation. Creativity and Innovation Management, 3-8.

Hult, G.T., \& Ferrell, O.C. (1997). Global organizational learning capacity in purchasing: Construct and measurement. Journal of Business Research, 40(2), 97-111.

Ju, T.L., Li, C., \& Lee, T. (2006) A contingency model for knowledge management capability and innovation, Industrial Management \& Data Systems, 106 (6), 855-877.

Jude-York, D. A. (1991). Organizational learning climate, self-directed learners, and performance at work [Unpublished doctoral dissertation]. The Fielding Institute, Santa Barbara, CA.

Kang, S.C., Morris, S.S., \& Snell, S. A. (2007). Relational archetypes, organizational learning, and value creation: Extending the human resource architecture. Academy of Management Review, 32 (1), 236-56.

Kline, R. B. (2005). Principles and Practice of Structural Equation Modeling (2nd ed.). Guilford Press, New York, NY.

Leavy, B. (1998). The concept of learning in the strategy field: Review and outlook. Management Learning, 29 (4), 447-66.

Levitt, B., \& March, J. (1988). Organizational learning. Annual Review of Sociology, 14, 31940 .

Lin, C., \& Kuo, T. (2007). The mediate effect of learning and knowledge on organizational performance, Industrial Management \& Data Systems, 107 (7), 2007, 1066-83.

Mahalanobis, P. C. (1936). On the generalized distance in statistics. Proceedings of the National Institute of Science, Calcutta 2, 49-55.

Mills, D.C., \& Friesen, B. (1992). The learning organization. European Management Journal, 10 (2), 146-56.

Neilson, R. (1997). Collaborative technologies \& organizational learning. Idea Group Publishing, Hersey, PA. 
Norusis, M. J. (1994). SPSS professional statistics 6/1, SPSS. Chicago, IL.

Pace, R.W., Regan, L., Miller, P., \& Dunn, L. (1998). Natural growth goals and short-term training: a boomerang effect. International Journal of Training \& Development, 2 (2), $128-40$.

Pedler, M., Burgoyne, J., \& Boydell, T. (1997). The learning Company. McGraw-Hill Publishing Company, London.

Ruiz-Mercader, J., Merono-Cerdan, A.L., \& Sabater-Sanchez, R. (2006). Information technology and learning: their relationship and impact on organizational performance in small business. International Journal of Information Management, 26 (1), 16-29.

Senge, P. (1990). The fifth discipline. Random House, London.

Shakya A. (2012). Organizational learning and performance in Nepalese service sector [Unpublished PhD thesis]. Department of Management, Tribhuvan University: Kathmandu, Nepal.

Sinkoula, J. M., Baker, W. E., \& Ordewier, T. (1997). A framework for market-based organizational learning: linking values, knowledge, and behavior. Journal of the Academy of Marketing Science, 25 (4), 305-18.

Theriou, G. N., \& Chatzoglou, P. D. (2008). Enhancing performance through best HRM practices, organizational learning and knowledge management: a conceptual framework. European Business Review, 20 (3), 185-207.

Thite, M. (2004). Strategic positioning of HRM in knowledge-based organizations. The Learning Organization, 11 (1), 28-44.

Ulrich, D., Jick, T., \& Von Glinow, M. (1993). High-impact learning: Building and diffusing learning capability. Organizational Dynamics, 22, 52-66.

Watkins, K. E., \& Marsick, V. J. (1993). Sculpting the learning organization: Lessons in the art and science of systemic change. San Francisco: Jossey-Bass.

Zikmund, W. G. (2003). Business research methods (7th ed.). Thomson, South-Western, Mason, $\mathrm{OH}$. 